\title{
Downward trends in the prevalence of childhood overweight in the setting of 12-year school- and community-based programmes
}

\author{
Monique Romon ${ }^{1, *}$, Agnes Lommez ${ }^{2}$, Muriel Tafflet $^{3}$, Arnaud Basdevant ${ }^{4}$, \\ Jean Michel Oppert ${ }^{4}$, Jean Louis Bresson ${ }^{5}$, Pierre Ducimetière ${ }^{3}$, Marie Aline Charles ${ }^{3}$ \\ and Jean Michel Borys ${ }^{2}$ \\ 'Lille 2 University Hospital, Service de Nutrition, EA2694, Faculté de Médecine, Place de Verdun, F-59045 Lille \\ Cedex, France: ${ }^{2}$ The Fleurbaix-Laventie Ville Santé Association, Laventie, France: ${ }^{3}$ INSERM Unit 780/Université \\ Paris Sud, Villejuif, France: ${ }^{4}$ Université Pierre et Marie Curie/Department of Nutrition, Pitié-Salpêtrière Hospital \\ (AP-HP)/Human Nutrition Centre lle-de-France (CRNH-ldF), Paris, France: ${ }^{5}$ Hôpital des Enfants Malades, \\ Paris, France
}

Submitted 18 January 2008: Accepted 28 0ctober 2008: First published online 23 December 2008

\begin{abstract}
Objective: A school-based nutrition information programme was initiated in 1992 in two towns in northern France (Fleurbaix and Laventie, FL) and was followed by a number of community-based interventions. We took the opportunity to measure the outcomes in terms of childhood obesity and overweight over the next 12 years.

Design: Repeated, cross-sectional, school-based survey. For the school years beginning in 1992, 2000, 2002, 2003 and 2004, the height and weight of all 5- to 12-year-old children attending school were measured in FL. In 2004, the same assessments were made in two comparison towns with similar socio-economic characteristics but no intervention.

Setting: Fleurbaix and Laventie (intervention towns), Bois-Grenier and Violaines (comparison towns), northern France.

Subjects: In 2002, 2003 and 2004, respectively 515, 592 and 633 children were measured in FL (participation rate of $95-98 \%$ of all eligible individuals); in the comparison towns, 349 children were measured in the 2004 school year (98\% of the towns' school population).

Results: After an initial increase, trends in mean BMI and prevalence of overweight started to reverse. Compared with 2002, the age-adjusted OR for overweight in FL was significantly lower in 2003 and 2004 (but for girls only). In the 2004 school year, the overweight prevalence was significantly lower in FL (8.8\%) than in the comparison towns $(17 \cdot 8 \%, P<0 \cdot 0001)$.

Conclusion: These data suggest that, over a long period of time, interventions targeting a variety of population groups can have synergistic effects on overweight prevalence. This gives hope that it is possible to reverse trends towards increasing overweight by actions at the community level.
\end{abstract}

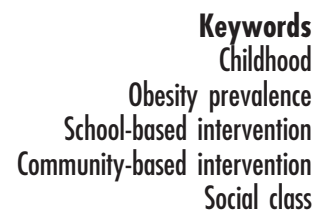

Keywords

Obesity prous

School-based intervention

Social class
In view of its increasing prevalence over the past two decades, childhood obesity is now considered a serious public health concern. In the USA, the prevalence of overweight in children and adolescents increased from $11 \%$ in $1988-94^{(1)}$ to $17 \%$ in $2003-4^{(2)}$. Similar trends are observed in Europe ${ }^{(3,4)}$ and in other parts of the world. Furthermore, the risk of overweight or obesity is unequally distributed between social classes ${ }^{(5-7)}$.

The prevention of obesity in general (and childhood obesity in particular) in an 'obesogenic' environment has become a true challenge. There are few controlled studies on the prevention of overweight and obesity in children and adolescents. Furthermore, these studies differ in terms of their strategy, setting and duration, and thus do not allow general conclusions to be drawn concerning the value of preventive measures ${ }^{(8)}$. A recent review of the literature evaluated twenty-four studies involving a total of 25896 children; eight of the studies reported that intervention had positive effects on the prevalence of obesity $^{(9)}$. However, the authors of the review were not able to determine any correlations between the type of intervention and its subsequent success (or failure). 
They suggested that a combination of long-term actions (promoting healthy dietary habits and physical activity throughout society) should have more powerful effects than measures limited to the school environment alone. Currently, most studies are school-based and there is a lack of reports on long-term programmes.

For over 12 years, we have had the opportunity to monitor a population exposed to a nutritional and physical activity information programme, the FleurbaixLaventie Ville Santé (FLVS) study. Fleurbaix and Laventie (FL) are two small towns in northern France. Three different periods can be distinguished: the first period (1992-7) focused on nutrition education in schools; the second period (1997-2002) was a longitudinal observational study on the determinants of weight changes; and the third period (2002-7) targeted physical activity and nutrition in the FL population as a whole via a series of community-based actions. The aim of the present paper is to describe BMI trends and changes in the prevalence of childhood overweight in this setting. The analysis takes into account the influence of parental social class. The prevalence of childhood overweight in the 2004-5 school year in FL was compared with that in two comparison towns (CT) with similar socio-economic backgrounds but no prevention programme in operation.

\section{Methods}

\section{Overview of the FLVS studies}

The two towns (FL) were the setting of three consecutive studies (FLVS I to III).

\section{FLVS I (1992-7)}

The aim of the FLVS I study ${ }^{(10,11)}$ was to evaluate the effects of a school-based nutrition education programme on the eating habits of the whole family. The programme consisted of both knowledge-oriented and practical approaches to nutrition. This stage was a school-based intervention and addressed children only.

The knowledge-oriented approach aimed at improving children's knowledge of the characteristics of foods and nutrients, healthy eating habits, and food processing and labelling, and was implemented throughout the teaching syllabus. This education programme was set up by the school teachers themselves ( $n$ 44). Teachers had been trained in the basics of nutrition by nutritionists and dietitians and had developed their pedagogical methodology under the control of the Regional Board of Education (a senior counsellor was in charge of the project). During the first period there was no special focus on physical activity.

Through a range of practical, cross-cutting initiatives, the practical approach promoted pleasant, affordable and diversified food, discovery meals in school cafeterias, cooking classes, visits to farms and various food shops, and family breakfasts organized in schools with monitoring from dietitians.

The activities were originally intended to last for 5 years but are still running in all FL schools.

FLVS II (1997-2002)

FLVS II ${ }^{(12-15)}$ was a longitudinal epidemiological study to investigate the determinants of weight and fat mass changes in the FL population. Every two years, 294 families living in FL had a clinical examination and were administered questionnaires about food habits, eating behaviour and physical activity.

This stage was supposed to be an observational study without intervention; however, the school-based interventions of the first stage were maintained and there was a steadily increasing commitment of the community at large so that progressively the intervention addressed both children and adults.

\section{FLVS III (2002-7)}

FLVS III comprised two parts. First, in 2003, a health check-up was offered at home to 3000 volunteers from the FL population. It included a fasting blood sample, a clinical examination and a questionnaire aiming at screening unhealthy habits (smoking, physical inactivity, alcohol consumption). Second, from 2004 onwards, subjects identified on the basis of this initial check-up (individuals with overweight, high blood pressure, high level of sedentary behaviour, unhealthy eating habits, hyperlipidaemia and smokers) were offered familyoriented advice on healthy eating and physical activity provided by a dietitian, who referred to the general practitioner in cases of identified health problems (including childhood obesity).

From 1999 on, the community at large became increasingly committed to the programme. Two dietitians were employed to perform interventions in schools and associations and at various meetings in the town for both children and adults. The town councils supported actions in favour of physical activity, new sporting facilities were built and sport educators were employed to promote physical activity in primary schools, walking-to-school days were organized, and family activities were also organized. Various local stakeholders (general practitioners, pharmacists, shopkeepers, sporting and cultural associations) set up family activities focused on a 'healthy lifestyle'.

Over the whole period covered by the present report (1992-2007), regular communication including newsletters (three per annum) and press releases (one per annum) supported the project. Media interest about the programme was important during the period: 212 articles appeared in local newspapers, 190 in the medical press and 208 in the national press, and there were twenty-five television reports and seventy-five radio reports. 


\section{The comparison towns}

Two CT (Bois-Grenier and Violaines, located in the same general area as FL and with similar socio-economic characteristics) were selected in 1992, when the first nutritional intervention programme began. In the same year, volunteer families in the CT participated in a dietary survey ${ }^{(10)}$. No information programmes or interventions related to nutrition or physical activity were performed in the CT over the period in question (1992-2005).

\section{Subjects}

In 1992, 2000 ${ }^{(16)}$ and then annually from 2002 to 2004 , body weight and height were measured in the entire population of 5- to 12-year-old children attending schools in FL. These measurements were performed during the school year, which runs from early September to early July.

Data collected in 1992 and 2000 have been described previously ${ }^{(16)}$. In 2002, 2003 and 2004, we measured 515, 592 and 633 children, respectively (corresponding to a participation rate of $95-98 \%$ of all eligible individuals).

In the CT, a total of 349 children were measured in the 2004-5 school year (98\% of the towns' school population).

\section{Anthropometric methods and definition of overweight}

The same group of research nurses measured all children and collected all other relevant data.

Weight was determined in light clothes (without shoes) to the nearest $0 \cdot 1 \mathrm{~kg}$, using either a calibrated scale for 5- and 6-year-olds or a bipodal bioimpedance device (model TBF 310; Tanita, Tokyo, Japan) for 7- to 12-yearolds. Standing height (without shoes) was measured to the nearest $0.5 \mathrm{~cm}$. BMI was calculated as weight divided by the square of height $\left(\mathrm{kg} / \mathrm{m}^{2}\right)$. Overweight prevalence was determined using the gender- and age-specific cutoffs according to the International Obesity Taskforce (6 month categories) published by Cole et al. ${ }^{(17)}$.

\section{Sociodemographic data}

Data on parental occupation and year of arrival in FL and CT were collected in June 2005, via a telephone interview. Parental occupation was defined by the occupation of the father in a two-parent family or by that of the single parent in a single-parent family ${ }^{(18)}$. The data were categorized into four classes: class I, professional and managerial occupations; class II, intermediate occupations (employees, own-account workers); class III, lower occupations (lower technical occupations, semi-routine and routine occupations); and class IV, unemployed.

\section{Statistical analysis}

Comparisons between 1992 and 2000 have been published previously ${ }^{(16)}$. Overall prevalences of overweight in 1992, 2000 and 2004 are given with 95\% confidence intervals.
Our statistical analysis focused on the three school years beginning in 2002, 2003 and 2004. BMI was compared between the different years by using a multivariate mixed model that took account of repeated observations (the SAS MIXED procedure, with an unstructured variance-covariance matrix), since some of the children were represented in the survey at several successive annual examinations. We adjusted the model for age and for height, since BMI was correlated with height in these children (Spearman correlation $=0.40$ for boys and girls, $P<0 \cdot 0001)$. The adjustment for height is discussed elsewhere ${ }^{(16)}$. Prior to these analyses, BMI values were log-transformed in order to normalize their distribution.

The odds ratios for the age-adjusted prevalence of overweight were calculated using generalized estimation equations (the SAS GENMOD procedure) which take repeated observations into account.

We also modelled the children's BMI and overweight status in 2004 as a function of the following explanatory variables in a multivariate linear regression model: parental social status, time spent living in the intervention towns, age, gender and height.

Comparisons between FL and the CT were performed with multivariate linear regression models adjusted for height and age for weight and BMI, and with Pearson $\chi^{2}$ tests for overweight prevalence (by gender and social class).

The SAS statistical software package version 9·1 (SAS Institute Inc., Cary, NC, USA) was used for all analyses. The significance threshold was set to $P<0 \cdot 05$.

\section{Results}

\section{Trends in overweight prevalence in FLVS children (1992-2004)}

Figure 1 shows the changes over time in the prevalence of childhood overweight (including obesity). Between 1992 and 2000, there was an increase in BMI and overweight prevalence $^{(16)}$. From 2000 to 2004, there was a decrease in the prevalence of overweight which was more pronounced in girls. For girls and boys taken together, the overweight prevalence was $13 \cdot 2 \%$ (sixty-eight children), $10 \cdot 5 \%$ (sixty-two children) and $8 \cdot 8 \%$ (fifty-six children) in 2002, 2003 and 2004, respectively. For the same years, the prevalence was $9 \cdot 5 \%, 7 \cdot 7 \%$ and $7 \cdot 4 \%$ for the boys and $17 \cdot 1 \%, 13 \cdot 6 \%$ and $10 \cdot 4 \%$ for the girls. When the years 1992 and 2004 are compared, there was no significant difference in the prevalence of overweight for either boys or girls.

The adjusted anthropometric characteristics and odds for the prevalence of overweight (including obesity) are shown in Table 1 . The adjusted BMI decreased significantly from 2002 to 2004, for both girls and boys. However, when compared with 2002, the age-adjusted OR for overweight in 2003 and 2004 was significantly lower only for girls. 


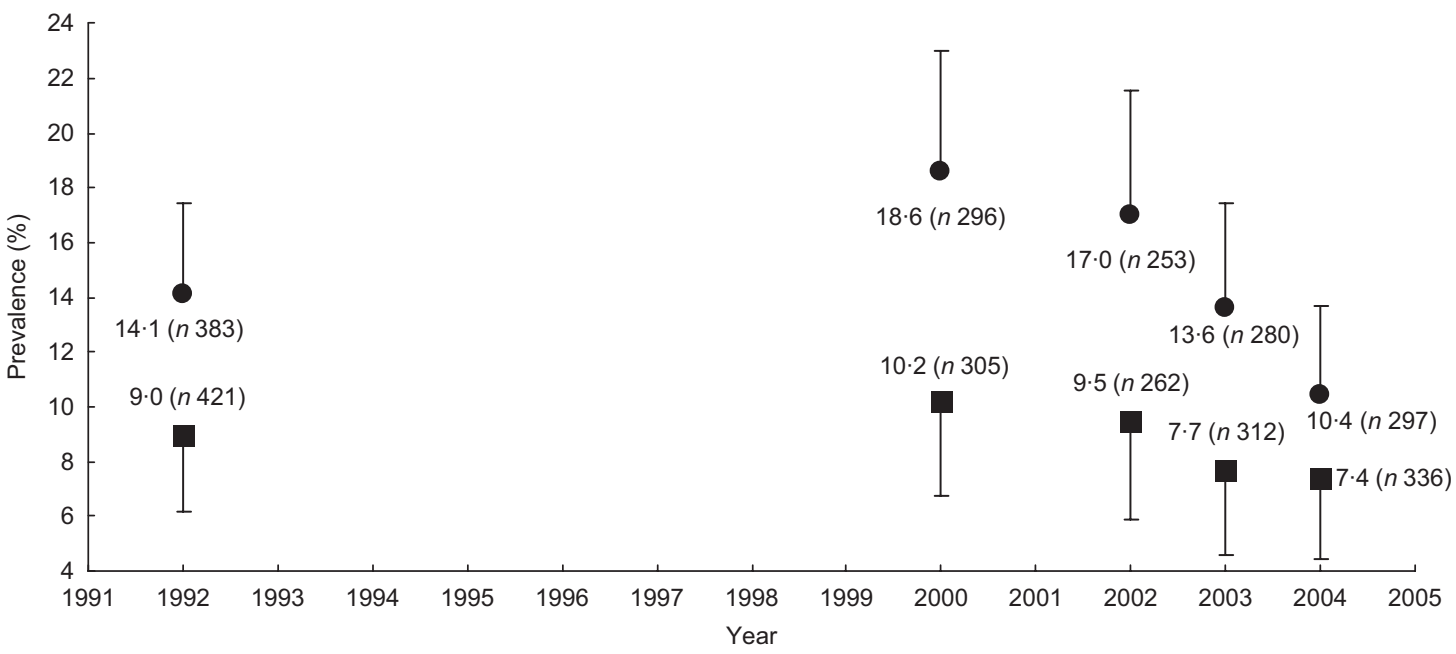

Fig. 1 Changes over time in overweight (including obesity) prevalence in boys $(\boldsymbol{\square})$ and girls (0) since the start of the Fleurbaix-Laventie Ville Santé (FLVS) study. Values are means with their $95 \%$ confidence intervals represented by vertical bars

\section{Multivariate analysis of the 2004 BMI data}

Our analysis revealed that only parental social class $(P=0 \cdot 01)$ and height $(P=0 \cdot 001)$ were significantly related to BMI. Multivariate logistic regression analysis of overweight status yielded the same results (data not shown).

\section{Comparison between intervention and comparison towns}

\section{BMI and prevalence of overweight}

Mean age, weight, BMI and overweight prevalence in 2004 for boys and girls in the CT are shown in Table 2, in comparison with FL. For boys, mean age was significantly higher in the CT. When adjusted for age and height, BMI was significantly higher in the CT than in FL for both genders. The crude overweight prevalence was significantly higher in the CT than in FL for both genders. For girls and boys taken together, the prevalence was $8 \cdot 8 \%$ in $\mathrm{FL}$ and $17 \cdot 8 \%$ in the CT $(P<0 \cdot 0001)$.

\section{Influence of social class}

The two sets of towns did not differ in terms of social class distribution. Classes I to IV represented respectively $15 \cdot 7 \%(n 53), 53 \cdot 2 \%(n 180), 27 \cdot 5 \%(n 93)$ and $3 \cdot 5 \%(n$ 12) for the CT and $17 \cdot 1 \%$ ( $n$ 107), $52 \cdot 3 \%$ ( $n 327), 26 \cdot 2 \%$ ( $n$ 164) and $4 \cdot 3 \%(n 27)$ for FL $(P=0 \cdot 8)$.

Figure 2 shows the prevalence of overweight in CT and FL as a function of parental social class. Class IV was not included in the figure because of the small sample size. In both sets of towns, there was a clear between-class difference $(P=0.003$ for FL, $P=0.005$ for CT), with a higher prevalence for class III in FL and for classes II and III in CT. Indeed, the disparity between the two sets of towns in terms of overweight prevalence was explained by the prevalence differences in classes II $(P=0 \cdot 0004)$ and III $(P=0 \cdot 02)$.

\section{Discussion}

The aim of the present paper was to analyse recent trends in the prevalence of childhood overweight in a community which has been exposed to nutritional interventions for 12 years. In the intervention towns, after an initial rise, there was a significant decrease in mean BMI and the prevalence of overweight tended to decrease. Moreover, in 2004, the overweight prevalence was significantly lower when compared with nearby comparison towns.

There is now a growing body of data on the prevention of childhood obesity. In general, all school-based interventions aimed at preventing overweight and obesity produce some improvement in health knowledge and health-related behaviour but, to date, most have not had a significant impact on the weight status of the participating children ${ }^{(19-23)}$. Studies using targeted prevention strategies also improved health-related behaviour and were most successful (in terms of weight status) when parents were involved in the intervention ${ }^{(24)}$. The follow-up times vary considerably from study to study. Furthermore, in most cases, the length of time over which interventions were being conducted was too short to produce an identifiable modification of weight status. More recent studies have shown encouraging results. The Kiel Obesity Prevention Study (KOPS) combined school-based interventions for overweight children and family-based interventions for their families. The preliminary results of the 4 -year follow-up showed a small decrease in the prevalence of overweight in 9- to 11-year-old girls. However, the prevalence of overweight was very high in the nonintervention group $(60 \cdot 0 \%)$, relative to the intervention group $(46 \cdot 2 \%)^{(25)}$. A recent study has published the 4-year follow-up results after a 6-year health and nutrition programme in primary schools; the mean BMI of the 
control group was higher than in the intervention group. However, this was a longitudinal study and the follow-up assessment was based on only $60 \%$ of the initial study population ${ }^{(26)}$. In contrast, the results of our cross-sectional study suggest that weight trends can indeed be modified at the population level.

Our results span over a 12-year follow-up period. The first interventional study started in 1992. At the time, childhood obesity was not considered to be a public health problem; in fact, the programme focused on improving nutritional knowledge and the objective was to see whether school-based information would improve dietary habits at home. Furthermore, this first study did not target increased physical activity. Over the next five years, no interventions (other than provision of nutritional information in schools) took place - only the observational study of the families was pursued. However, given that $60 \%$ of the families were involved in this follow-up, there was ongoing involvement of schools and growing community interest. Even though the initial focus was not on obesity and physical activity, support from the town councils led to increased promotion of physical activity. The first evaluation (conducted at the end of the first intervention) showed a non-significant trend towards an increased prevalence of overweight between 1992 and $2000^{(16)}$. Taken in isolation, these initial results could have been interpreted as indicating the school-based programme's lack of efficacy. In fact, this was the first step in an awareness-raising process for FL families - a process which has gradually intensified over time and prompted the initiation of a whole-community intervention programme in 2000. It is noteworthy that children at school in 2002 were born between 1991 and 1997, i.e. after the beginning of the first nutritional intervention in FL (1992). It is tempting to suggest that the nutrition-oriented context in FL was more effective in preventing overweight in children born after 1992 than in reversing overweight in their older counterparts. Since the two towns are now associated in the media with a healthy lifestyle, our data could also have been biased by the arrival of families who place greater importance on good health. However, our results do not reveal any differences between families living in FL at the start of the intervention and those who arrived afterwards.

Our results confirm the strong influence of parental social class on the risk of overweight and obesity. For children from high social classes, there was no difference between the CT and FL - mainly because there was no increase in overweight prevalence in this population. These results are in accordance with a previous study performed in the same area, which showed that between 1989 and 1999, there was no change in either mean BMI or overweight prevalence in 5-year-old children from the highest social class ${ }^{(4)}$. Recently, Stamatakis et al. have reported similar results in 5- to 10-year-old English children: those from higher-income households had 
Table 2 Age, weight, height, BMI and overweight prevalence comparisons between schoolchildren in the intervention (FL) and comparison towns (CT) in 2004: Fleurbaix-Laventie Ville Santé (FLVS) study

\begin{tabular}{|c|c|c|c|c|c|c|c|c|c|c|}
\hline & \multicolumn{5}{|c|}{ Boys } & \multicolumn{5}{|c|}{ Girls } \\
\hline & \multicolumn{2}{|c|}{$\mathrm{FL}(n$ 336) } & \multicolumn{2}{|c|}{ CT $(n 180)$} & \multirow[b]{2}{*}{$P$} & \multicolumn{2}{|c|}{$\mathrm{FL}(n$ 297) } & \multicolumn{2}{|c|}{ CT $(n$ 169) } & \multirow[b]{2}{*}{$P$} \\
\hline & Mean & SE & Mean & SE & & Mean & SE & Mean & SE & \\
\hline Age (years) & $8 \cdot 0$ & 0.1 & $8 \cdot 4$ & $0 \cdot 1$ & 0.004 & $7 \cdot 8$ & $0 \cdot 1$ & $8 \cdot 1$ & $0 \cdot 1$ & $0 \cdot 1$ \\
\hline Height $(\mathrm{cm})$ & $129 \cdot 9$ & 0.6 & $131 \cdot 3$ & 0.9 & 0.2 & $127 \cdot 2$ & $0 \cdot 7$ & $129 \cdot 0$ & 0.9 & $0 \cdot 1$ \\
\hline \multirow[t]{2}{*}{ Weight (kg) } & $27 \cdot 0$ & 0.5 & $30 \cdot 0$ & 0.6 & 0.0002 & $26 \cdot 1$ & 0.5 & $28 \cdot 3$ & 0.6 & 0.006 \\
\hline & Mean & $95 \% \mathrm{Cl}$ & Mean & $95 \% \mathrm{Cl}$ & & Mean & $95 \% \mathrm{Cl}$ & Mean & $95 \% \mathrm{Cl}$ & \\
\hline BMI $\left(k g / m^{2}\right)$ & $15 \cdot 6$ & $15 \cdot 4,15 \cdot 9$ & $16 \cdot 7$ & $16 \cdot 4,17 \cdot 0$ & $<0.0001$ & $15 \cdot 7$ & $15 \cdot 4,15 \cdot 9$ & $16 \cdot 4$ & $16 \cdot 1,16 \cdot 8$ & 0.0004 \\
\hline BMI $\left(\mathrm{kg} / \mathrm{m}^{2}\right) \dagger$ & $15 \cdot 7$ & $15 \cdot 5,15 \cdot 9$ & $16 \cdot 5$ & $16 \cdot 2,16 \cdot 8$ & 0.02 & $15 \cdot 7$ & $15 \cdot 5,15 \cdot 9$ & $16 \cdot 4$ & $16 \cdot 0,16 \cdot 7$ & 0.005 \\
\hline Overweight prevalence (\%)‡ & $7 \cdot 4$ & $4 \cdot 6,10 \cdot 2$ & $19 \cdot 4$ & $13 \cdot 6,25 \cdot 2$ & $<0.0001$ & $10 \cdot 4$ & $6.9,13.9$ & $16 \cdot 0$ & $10 \cdot 5,21 \cdot 5$ & 0.08 \\
\hline
\end{tabular}

tAdjusted for age.

flncluding obesity, according to gender- and-age-specific BMI cut-offs of the International Obesity Taskforce ${ }^{(17)}$.

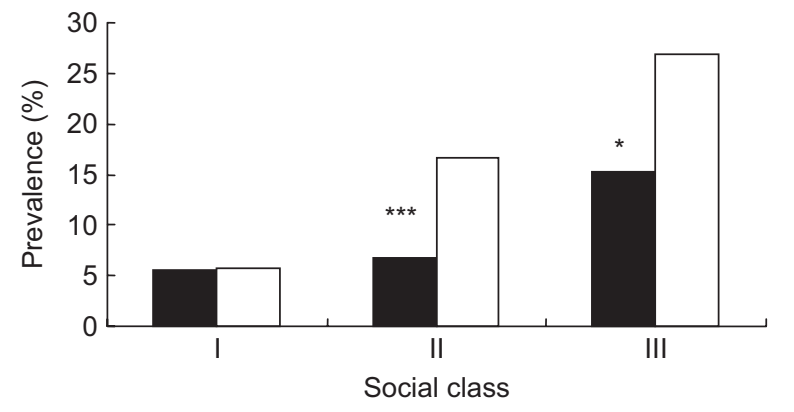

Fig. 2 Prevalence of overweight (including obesity) in 2004 in Fleurbaix and Laventie (intervention towns; $\mathbf{0}$ ) and nearby comparison towns $(\square)$ as a function of parental social class: Fleurbaix-Laventie Ville Santé (FLVS) study. The social classes were defined as follows: class I, professional and managerial occupations; class II, intermediate occupations (employees, own-account workers); class III, lower occupations (lower technical occupations, semi-routine and routine occupations). Significantly different from the comparison towns ( $\chi^{2}$ test): ${ }^{\star} P<0 \cdot 05,{ }^{* * *} P<0.001$

lower odds $(\mathrm{OR}=0 \cdot 74)$ of being obese than their peers from lower social classes ${ }^{(7)}$. Many earlier studies have examined the relationship with parental socio-economic status (SES); most reported an inverse correlation between SES and obesity ${ }^{(27-29)}$. Some studies found that the lowest overweight prevalence was observed in the two most extreme socio-economic groups ${ }^{(30)}$. This lack of inter-study consistency may be explained by differences in the study populations ${ }^{(31)}$ or SES indicators examined. The indicator used in the present study has been shown to be a good measure of life chances ${ }^{(18)}$.

A limitation of the present work is that we did not have the data concerning the schools attended by the children, and therefore we were not able to adjust for a school clustering effect. A second limitation is that we lack the corresponding data for the CT. At the beginning of the FLVS study, an analysis of a sub-sample of families (in both FL and the CT) enrolled in a dietary habits study in 1992 did not show any differences in terms of the prevalence of childhood overweight (12.6\% in the CT and $11.2 \%$ in FL; NS). However these results were based on reported and not measured weight and height (L Lafay, JM Borys, MA Charles and M Romon, unpublished results). It has been suggested that comparison of the impact of an intervention with a control group undergoing the same height and weight assessments could have the same sort of impact on the control children's behaviour as the intervention itself, and may thus lead to an underestimation of the latter's effect ${ }^{(8)}$. The prevalence that we now observe in the CT is very close to the prevalence observed around the same time in other French studies. In 1999, the overweight prevalence was $16.9 \%$ in 5 -year-olds ${ }^{(4)}$ and in 2000 it was $17 \cdot 9 \%$ in 7 - to 9-year-old children ${ }^{(32)}$. In 2000, the French Ministry of Health launched PNNS (Programme National Nutrition Santé - National Nutrition and Health Programme); we cannot exclude an effect of this Francewide intervention promoting healthy eating and physical activity at the national level (mostly through nationwide media campaigns). Results from the 2006 cross-sectional French survey showed that $14 \cdot 1 \%$ of children aged $3-10$ years were overweight ${ }^{(33)}$. These data, together with the 2005 comparison with the CT, suggest that the decreasing prevalence observed in FL does not reflect a decreasing prevalence of overweight in the country as a whole due to the PNNS campaign.

The present study provided a good opportunity to perform long-term follow-up of a population with repeated, cross-sectional studies. Its main finding is that, at the community level, a reversal of the trend towards increasing childhood overweight can be observed. These data are in line with two recent studies ${ }^{(34,35)}$; these studies are short-term studies and long-term maintenance of their results remains to be demonstrated. In all cases, the changes occurred in the context of a number of interventions which were not merely limited to the school environment. Furthermore, the FLVS study shows that the social classes at greater risk of overweight may indeed benefit from nutritional and health-related interventions. 
The absence of measurement of mediating variables prevents us from defining which aspects of the interventions were actually effective. If there is a causal link between the interventions and the decrease in overweight prevalence, it is worth emphasizing that a follow-up period of more than 10 years was needed to yield these results. The first years of the intervention were aimed at improving nutrition knowledge and did not target behaviour as such. Finally, the present study suggests that long-term results may be achieved through ongoing support from society as a whole, including parents, schools and government agencies ${ }^{(36)}$.

\section{Acknowledgements}

The Fleurbaix-Laventie Ville Santé Study was supported by grants from the CEDUS (Centre for Sugar Research and Information), Fournier Pharma, Lesieur, Nestlé France, Produits Roche, Go-Sports companies, and the Conseil Regional Nord Pas de Calais. The authors declare that they have no conflict of interest. M.R. conceptualized and wrote the manuscript; A.L. was involved in the design of the study and data collection; M.T. performed the statistical analyses; A.B. participated in the conceptualization and design of the study and reviewed the paper; J.M.O. participated in the conceptualization and design of the study, data analysis and contributed to writing the manuscript; J.L.B. participated in data analysis and reviewed the paper; P.D. participated in data analysis and reviewed the paper; M.A.C. participated in data analysis and contributed to writing the manuscript; J.M.B. participated in the conceptualization and design of the study and contributed to writing the manuscript. The help of D. Fraser in editorial revision of the manuscript was greatly appreciated.

\section{References}

1. Ogden CL, Flegal KM, Carroll MD \& Johnson CL (2002) Prevalence and trends in overweight among US children and adolescents, 1999-2000. JAMA 288, 1728-1732.

2. Ogden CL, Carroll MD, Curtin LR, McDowell MA, Tabak CJ \& Flegal KM (2006) Prevalence of overweight and obesity in the United States, 1999-2004. JAMA 295, 1549-1555.

3. Bundred P, Kitchiner D \& Buchan I (2001) Prevalence of overweight and obese children between 1989 and 1998: population based series of cross sectional studies. BMJ 322, 326-328.

4. Romon M, Duhamel A, Collinet N \& Weill J (2005) Influence of social class on time trends in BMI distribution in 5-year-old French children from 1989 to 1999. Int J Obes (Lond) 29, 54-59.

5. Lamerz A, Kuepper-Nybelen J, Wehle C, Bruning N, TrostBrinkhues G, Brenner $H$, Hebebrand $J$ \& HerpertzDahlmann B (2005) Social class, parental education, and obesity prevalence in a study of six-year-old children in Germany. Int J Obes (Lond) 29, 373-380.

6. Mei Z, Scanlon KS, Grummer-Strawn LM, Freedman DS, Yip R $\&$ Trowbridge FL (1998) Increasing prevalence of overweight among US low-income preschool children: the Centers for Disease Control and Prevention pediatric nutrition surveillance, 1983 to 1995. Pediatrics 101, E12.

7. Stamatakis E, Primatesta P, Chinn S, Rona R \& Falascheti E (2005) Overweight and obesity trends from 1974 to 2003 in English children: what is the role of socioeconomic factors? Arch Dis Child 90, 999-1004.

8. Summerbell CD, Waters E, Edmunds LD, Kelly S, Brown T \& Campbell KJ (2005) Interventions for preventing obesity in children. Cochrane Database Syst Rev issue 3, CD001871.

9. Flodmark CE, Marcus C \& Britton M (2006) Interventions to prevent obesity in children and adolescents: a systematic literature review. Int J Obes (Lond) 30, 579-589.

10. Lafay L, Vray M, Boute D \& Basdevant A (1998) Food and nutritional data for a population from northern France: the Fleurbaix Laventie Ville Sante (FLVS) Study. Rev Epidemiol Sante Publique 46, 263-275.

11. Lafay L, Mennen L, Basdevant A, Charles MA, Borys JM, Eschwege E \& Romon M (2000) Does energy intake underreporting involve all kinds of food or only specific food items? Results from the Fleurbaix Laventie Ville Sante (FLVS) study. Int J Obes Relat Metab Disord 24, 1500-1506.

12. de Lauzon-Guillain B, Basdevant A, Romon M, Karlsson J, Borys JM \& Charles MA (2006) Is restrained eating a risk factor for weight gain in a general population? Am J Clin Nutr 83, 132-138.

13. de Lauzon-Guillain B, Romon M, Deschamps V, Lafay L, Borys JM, Karlsson J, Ducimetiere P \& Charles MA (2004) The Three-Factor Eating Questionnaire-R18 is able to distinguish among different eating patterns in a general population. J Nutr 134, 2372-2380.

14. Kettaneh A, Heude B, Lommez A, Borys JM, Ducimetiere P \& Charles MA (2005) Reliability of bioimpedance analysis compared with other adiposity measurements in children: the FLVS II Study. Diabetes Metab 31, 534-541.

15. Romon M, Lafay L, Bresson JL, Oppert JM, Borys JM, Kettaneh A \& Charles MA (2004) Relationships between physical activity and plasma leptin levels in healthy children: the Fleurbaix-Laventie Ville Sante II Study. Int J Obes Relat Metab Disord 28, 1227-1232.

16. Heude B, Lafay L, Borys JM, Thibult N, Lommez A, Romon M, Ducimetiere P \& Charles MA (2003) Time trend in height, weight, and obesity prevalence in school children from Northern France, 1992-2000. Diabetes Metab 29, 235-240.

17. Cole TJ, Bellizzi MC, Flegal KM \& Dietz WH (2000) Establishing a standard definition for child overweight and obesity worldwide: international survey. BMJ 320, 1240-1243.

18. Rose D \& Pevalin DJ (2001) The National Statistics Socioeconomics Classification Unifying Official and Sociological Approaches to the Conceptualisation and Measurement of Social Class. ISER Working Paper no. 2001-4. Colchester: University of Essex.

19. Caballero B, Clay T, Davis SM et al. (2003) Pathways: a school-based, randomized controlled trial for the prevention of obesity in American Indian schoolchildren. Am J Clin Nutr 78, 1030-1038.

20. Muller MJ, Danielzik S \& Pust S (2005) School- and familybased interventions to prevent overweight in children. Proc Nutr Soc 64, 249-254.

21. Sahota P, Rudolf MC, Dixey R, Hill AJ, Barth JH \& Cade J (2001) Randomised controlled trial of primary school based intervention to reduce risk factors for obesity. BMJ $\mathbf{3 2 3}$, 1029-1032.

22. Story M (1999) School-based approaches for preventing and treating obesity. Int $J$ Obes Relat Metab Disord 23, Suppl. 2, S43-S51.

23. Veugelers PJ \& Fitzgerald AL (2005) Effectiveness of school programs in preventing childhood obesity: a multilevel comparison. Am J Public Health 95, 432-435. 
24. Epstein LH, Valoski AM, Vara LS, McCurley J, Wisniewski L, Kalarchian MA, Klein KR \& Shrager LR (1995) Effects of decreasing sedentary behavior and increasing activity on weight change in obese children. Health Psychol 14, 109-115.

25. Danielzik S, Pust S, Landsberg B \& Muller MJ (2005) First lessons from the Kiel Obesity Prevention Study (KOPS). Int J Obes (Lond) 29, Suppl. 2, S78-S83.

26. Manios Y \& Kafatos A (2006) Health and nutrition education in primary schools in Crete: 10 years follow-up of serum lipids, physical activity and macronutrient intake. Br J Nutr 95, 568-575.

27. Danielzik S, Czerwinski-Mast M, Langnase K, Dilba B \& Muller MJ (2004) Parental overweight, socioeconomic status and high birth weight are the major determinants of overweight and obesity in 5-7 y-old children: baseline data of the Kiel Obesity Prevention Study (KOPS). Int $J$ Obes Relat Metab Disord 28, 1494-1502.

28. De Spiegelaere M, Dramaix M \& Hennart P (1998) Socioeconomic status and changes in body mass from 3 to 5 years. Arch Dis Child 78, 477-478.

29. Janssen I, Boyce WF, Simpson K \& Pickett W (2006) Influence of individual- and area-level measures of socioeconomic status on obesity, unhealthy eating, and physical inactivity in Canadian adolescents. Am J Clin Nutr 83, 139-145.

30. Moreno LA, Sarria A, Fleta J, Rodriguez G, Gonzalez JM \& Bueno M (2001) Sociodemographic factors and trends on overweight prevalence in children and adolescents in Aragon (Spain) from 1985 to 1995. J Clin Epidemiol 54, 921-927.

31. Livingstone MB, McCaffrey TA \& Rennie KL (2006) Childhood obesity prevention studies: lessons learned and to be learned. Public Health Nutr 9, 1121-1129.

32. Rolland-Cachera MF, Castetbon K, Arnault N, Bellisle F, Romano MC, Lehingue Y, Frelut ML \& Hercberg S (2002) Body mass index in 7-9-y-old French children: frequency of obesity, overweight and thinness. Int J Obes Relat Metab Disord 26, 1610-1616.

33. Lioret S, Maire B, Touvier M, Dubuisson C, Dufour A, Calamassi-Tran G, Volatier JL \& Lafay L (2008) Recent trends in childhood overweight in France. Int J Obes (Lond) 32, Suppl. 1, S207.

34. Sanigorski AM, Bell AC, Kremer PJ, Cuttler R \& Swinburn BA (2008) Reducing unhealthy weight gain in children through community capacity-building: results of a quasiexperimental intervention program, Be Active Eat Well. Int J Obes (Lond) 32, 1060-1067.

35. Foster GD, Sherman S, Borradaile KE, Grundy KM, Vander Veur SS, Nachmani J, Karpyn A, Kumanyika S \& Shults J (2008) A policy-based school intervention to prevent overweight and obesity. Pediatrics 121, e794-e802.

36. Ockene JK, Edgerton EA, Teutsch SM, Marion LN, Miller T, Genevro JL, Loveland-Cherry CJ, Fielding JE \& Briss PA (2007) Integrating evidence-based clinical and community strategies to improve health. Am J Prev Med 32, 244-252. 